\title{
INFLUENCE OF THE SIZE OF AORTIC VALVE PROSTHESES ON HEMODYNAMICS AND CHANGE IN LEFT VENTRICULAR MASS: IMPLICATIONS FOR THE SURGICAL MANAGEMENT OF AORTIC STENOSIS
}

José Ramón González-Juanatey, $\mathrm{MD}, \mathrm{PhD}$

José María García-Acuña, MD

Marino Vega Fernandez, MD

Antonio Amaro Cendón, MD, PhD

Victor Castelo Fuentes, MD

José Benito García-Bengoechea, $\mathrm{MD}, \mathrm{PhD}$

Miguel Gil de la Peña, MD, PhD
Discussion of aortic valve replacement has primarily concerned the choice between tissue and mechanical prostheses. Less emphasis has been placed on prosthesis size. Despite technical advances increasing prosthesis orifice area, small valves implanted in the unenlarged aortic root may not be significantly less obstructive than the stenotic native valves they replace. Methods: In this work we studied 52 patients (31 women, 21 men; mean age 59.2 years) in whom valve prostheses sized $19,21,23$, or $25 \mathrm{~mm}(30$ bioprostheses and 22 tilting disc valves) had been implanted to replace stenotic aortic valves. Most patients with 19 or $21 \mathrm{~mm}$ prostheses were women. Doppler and conventional echocardiographic studies were performed in the 10 days preceding the operation and between 10 and 40 months (mean 18 months) after the operation. The patients receiving larger valve sizes had significantly larger body surface areas than those receiving smaller valve sizes (mainly women). Results: No significant differences were observed between preoperative and postoperative diameters or left ventricular systolic function parameters, but left ventricular mass and mass index decreased in all four groups (albeit nonsignificantly in the $19 \mathrm{~mm}$ group, and with less statistical significance in the $21 \mathrm{~mm}$ group than in the 23 and $25 \mathrm{~mm}$ groups). Postoperative peak and mean transvalvular pressure drops were significantly greater in the $19 \mathrm{~mm}$ group than in the other groups, and the $21 \mathrm{~mm}$ group had significantly greater transvalvular pressure drops than the $25 \mathrm{~mm}$ group. Postoperative effective valve area was significantly smaller in the $19 \mathrm{~mm}$ group than in the $21 \mathrm{~mm}$ group, and significantly smaller in the $21 \mathrm{~mm}$ group than in the 23 and $25 \mathrm{~mm}$ groups. Conclusion: We conclude that despite undeniable recent improvements in the design of artificial heart valves, $19 \mathrm{~mm}$ aortic prostheses continue to create significant obstruction of the left ventricular outflow tract and, possibly as a consequence of this, fail to bring about significant reduction in left ventricular hypertrophy. (J Thorac Cardiovasc Surg 1996;112:273-80) li: general, replacing severely dysfunctional aortic valves improves performance and prognosis. The surgical management of patients with small aortic rings is nevertheless controversial because of the

\footnotetext{
From the Departments of Cardiology and Cardiac Surgery, Galician General Hospital and University of Santiago Faculty of Medicine, Santiago de Compostela, Spain.

Received for publication March 16, 1995; revisions requested June 20, 1995; revisions received August 9, 1995; accepted for publication Jan. 25, 1996.

Address for reprints: José Ramón González-Juanatey, MD, PhD, Departmento de Cardioloxía, Hospital Xeral de Galicia, Galeras s/n, 15705 Santiago de Compostela, Spain.

Copyright (C) 1996 by Mosby-Year Book, Inc

$0022-5223 / 96 \$ 5.00+0 \quad \mathbf{1 2} / \mathbf{1} / \mathbf{7 2 3 2 2}$
}

suboptimal hemodynamics of small sizes of even the most advanced types of prostheses; prognosis is worse for patients with small implanted valves than for those with larger prostheses. ${ }^{1-5}$

For patients having a small aortic ring, the usual alternative to small valve implantation is to reduce valve prosthesis-patient mismatch by implanting a larger valve after enlargement of the aortic ring. The drawback of this approach is that it increases the duration and, in principle, the risk of the operation. $^{4,6,7}$ Another alternative might be the use of valvular homografts, which have excellent hemodynamics but which are not readily available to most centers. $^{8}$

Aortic valve stenosis induces left ventricular hy- 
Table I. Intralaboratory variability of Doppler echocardiographic parameters in the prostheses and bioprostheses included in the study

\begin{tabular}{lc}
\hline & Percent \\
\hline Left ventricular outflow tract diameter & 4 \\
Peak velocity & 8 \\
Mean gradient & 11 \\
Effective orifice area & 10 \\
\hline
\end{tabular}

pertrophy ( $\mathrm{LVH})$ as an adaptive response to the chronic overload caused by the valve disease. LVH is the causal link between aortic valve stenosis and myocardiac ischemia, diastolic and systolic ventricular dysfunction, and ventricular arrhythmias associated with sudden death. A number of studies, mostly of patients with systemic arterial hypertension, have confirmed the adverse influence of LVH on life expectancy ${ }^{9}{ }^{10}$; among patients with aortic valve prostheses implanted to redress aortic stenosis, those with echocardiographically detected LVH have a significantly higher postoperative death rate than those without. ${ }^{11}$ After aortic valve replacement to reduce the obstruction to ejection, left ventricular mass (LVM) tends to decrease; this decrease may reduce the risk of ischemia, dysfunction, and electrical instability and in any case is known to be associated with improved cardiac performance and prognosis.

Doppler echocardiography is currently the standard technique for noninvasive evaluation of the structure and function of heart valve prostheses. Measurements of mean and peak transvalvular pressure drops, effective valve area, and cardiac output obtained by Doppler echocardiography correlate satisfactorily with those obtained by invasive methods. ${ }^{8,12-14}$

We report here the results of a retrospective study of the hemodynamics of various designs and sizes of aortic valve prosthesis and their relationship to postimplantation reduction in $\mathrm{LVH}$.

\section{Patients and methods}

Protocol. Between January 1989 and December 1994, 68 patients in our center underwent replacement of the aortic valve alone on account of predominantly aortic valvular stenosis. None of these patients underwent, or had previously undergone, a cardiovascular operation of any other kind. Thirty-seven other patients who were operated on for severe aortic stenosis in the same period were excluded from the study because they also had other types of cardiac disease: 18 had moderate or severe aortic insufficiency, 11 mitral valve disease, 5 coronary artery disease, 2 aortic insufficiency and cor- onary artery disease, and 1 mitral valve disease and coronary artery disease. The follow-up protocol of all 68 patients with "pure" aortic stenosis included evaluation of valve function by Doppler echocardiography. We studied retrospectively 52 of these patients who fulfilled the following criteria: (1) before the operation they had sinus rhythm and greater stenosis of a native aortic valve than of any other valve, and they had no other cardiac disease; (2) the operation consisted only in the implantation of an aortic valve prosthesis, with no aortic ring enlargement procedure; (3) a Doppler echocardiogram good enough for evaluation of left ventricular structure and function and aortic valve disease had been taken within the 10 days preceding the operation; and (4) 12 months or more after valve implantation the patients were in New York Heart Association (NYHA) functional classes I or II.

Of the 52 patients studied, 12 received $19 \mathrm{~mm}$ valves: 2 MitroFlow pericardial bioprostheses (MitroFlow International Inc., Richmond, Canada), 6 Labcor-Santiago pericardial bioprostheses (Labcor Laboratories, Belo Horizonte, Brazil), and 4 CarboMedics bileaflet prostheses (CarboMedics Inc., Austin, Tex.); 15 received $21 \mathrm{~mm}$ valves (1 MitroFlow pericardial bioprosthesis, 7 LabcorSantiago bioprostheses, and 7 CarboMedics valves); 16 received $23 \mathrm{~mm}$ valves (9 Labcor-Santiago bioprostheses and 7 CarboMedics valves); and 9 received $25 \mathrm{~mm}$ valves (5 Labcor-Santiago bioprostheses and 4 CarboMedics valves). All patients continued to have sinus rhythm during postoperative follow-up. Follow-up echocardiographic studies took place 10 to 40 months after the operations (mean 18 months).

Of the 16 patients with "pure" aortic stenosis not included in the study, only two had $19 \mathrm{~mm}$ valve prostheses. One of these, who was in NYHA class III, died suddenly 33 days after the operation and the other was excluded from the study because of atrial fibrillation before the operation. One year after the operation, no patient with a $19 \mathrm{~mm}$ prosthesis was in NYHA class III or IV.

Echocardiography. Echocardiograms were performed with a Hewlett-Packard Sonos 1000 apparatus (HewlettPackard Co., Palo Alto, Calif.) with $3.5 \mathrm{MHz}$ transducers for images and $2.5 \mathrm{MHz}$ transducers for Doppler effect measurements. All echocardiograms were recorded on SuperVHS videotape (Panasonic, Matsushita Electric Works, Osaka, Japan) for subsequent analysis.

M-mode measurements. M-mode echocardiograms were taken for measurement (in millimeters) of telediastolic interventricular septum thickness (IVST), left ventricular posterior wall thickness (PWT), and telediastolic (LVEDD) and telesystolic (LVESD) left ventricular diameters; simultaneous two-dimensional longitudinal or transverse parasternal views were used to ensure that the measurements were taken immediately above the papillary muscles. All measurements were repeated for four to six successive heartbeats, and the values accepted for each patient were the means of these four to six values.

LVM was calculated from Devereux and Reichek's formula $^{15}:$ LVM $($ in grams $)=1.04 \times([$ LVEDD + IVST + PWT] $)^{3}-$ LVEDD $\left.^{3}\right)-13.6$. 
Table II. Preoperative clinical and echocardiographic data

\begin{tabular}{|c|c|c|c|c|}
\hline & \multicolumn{4}{|c|}{ Valve size (no. of patients) } \\
\hline & $19 \mathrm{~mm}(12)$ & $21 \mathrm{~mm}(15)$ & $23 \mathrm{~mm}(16)$ & $25 \mathrm{~mm}(9)$ \\
\hline Age (yr) & $65.1 \pm 6.4$ & $59.7 \pm 8.1$ & $53.3 \pm 11.4$ & $58.8 \pm 12.6$ \\
\hline Body surface area $\left(\mathrm{m}^{2}\right)$ & $1.57 \pm 0.12$ & $1.64 \pm 0.11$ & $1.71 \pm 0.18$ & $1.78 \pm 0.17$ \\
\hline Gender $(\mathrm{M} / \mathrm{F})$ & $3 / 9$ & $5 / 10$ & $8 / 8$ & $5 / 4$ \\
\hline NYHA class (I/II/III/IV) & $0 / 2 / 8 / 2$ & $0 / 3 / 10 / 2$ & $0 / 6 / 8 / 2$ & $0 / 2 / 7 / 0$ \\
\hline PSG (mm Hg) & $108 \pm 36$ & $94 \pm 32$ & $96 \pm 45$ & $93 \pm 42$ \\
\hline $\mathrm{MSG}$ (mm Hg) & $62 \pm 23$ & $55 \pm 20$ & $51 \pm 28$ & $48 \pm 26$ \\
\hline EOA $\left(\mathrm{cm}^{2}\right)$ & $0.54 \pm 0.12$ & $0.63 \pm 0.09$ & $0.61 \pm 0.12$ & $0.58 \pm 0.13$ \\
\hline Fractional fiber shortening (\%) & $33 \pm 5$ & $34 \pm 4$ & $30 \pm 6$ & $30 \pm 5$ \\
\hline Ejection fraction $(\%)$ & $64 \pm 7$ & $67 \pm 6$ & $61 \pm 9$ & $60 \pm 9$ \\
\hline Systolic blood pressure ( $\mathrm{mm} \mathrm{Hg}$ ) & $128 \pm 12$ & $121 \pm 14$ & $130 \pm 14$ & $122 \pm 11$ \\
\hline Diastolic blood pressure $(\mathrm{mm} \mathrm{Hg}$ ) & $72 \pm 7$ & $68 \pm 8$ & $75 \pm 8$ & $69 \pm 6$ \\
\hline Heart rate (beats/min) & $84 \pm 14$ & $79 \pm 12$ & $76 \pm 11$ & $77 \pm 10$ \\
\hline
\end{tabular}

Age: $19 \mathrm{~mm}$ versus $23 \mathrm{~mm}, p<0.01$; body surface area: $19 \mathrm{~mm}$ versus $23 \mathrm{~mm}, p<0.05 ; 19 \mathrm{~mm}$ versus $25 \mathrm{~mm}, p<0.01$. NYHA, New York Heart Association; $P S G$, peak flow velocity; $M S G$, modified flow velocity; $E O A$, effective orifice area.

LVM index (LVMI, in grams per square meter) was defined as LVM/BSA, where BSA is body surface area in square meters. Left ventricular fractional shortening (percent) was calculated as $100 \times$ (LVEDD - LVESD)/ LVEDD. Left ventricular ejection fraction (percent) was calculated as $100 \times\left(\right.$ LVEDD $^{3}-$ LVESD $\left.^{3}\right) /$ LVEDD $^{3}$.

Doppler effect measurements. With the guidance of color flow images, systolic velocities in the outflow tract near the valve were measured in pulsed Doppler mode from the apical four-chamber view. Velocities through native and prosthetic aortic valves were measured in the continuous Doppler mode from apical, suprasternal, and right parasternal views; once the view giving the greatest velocities had been found, the velocities measured from this view during three cardiac cycles with durations close to the patient's mean beat-to-beat interval were averaged to yield a single value for that patient. Pulsed Doppler mode was used to search for increased velocities within the left ventricle by stepping the sample volume from the apex to the valve.

Peak and mean systolic transvalvular pressure drops calculated from peak and mean flow velocities by the modified Bernoulli equation are in this article denoted $P S G$ and $M S G$, respectively. $P S G c$ denotes peak pressure drops calculated by means of the Bernoulli equation with correction for prevalvular velocities: $\mathrm{PSGc}=4\left(\mathrm{Vvalv}^{2}-\right.$ $\mathrm{Vlvol}^{2}$ ), where Vvalv is the peak velocity through the prosthesis and Vlvot the peak velocity in the left ventricular outflow tract just below the prosthesis. ${ }^{16}$ The area (A) of the left ventricular outflow tract was calculated as $p(D / 2)^{2}$, where $D$ was the mean diameter of the tract in three successive images recorded at the beginning of systole from the longitudinal parasternal direction. Cardiac output $(\mathrm{CO})$ was calculated as A $\times$ VTTlvot $\times \mathrm{HR}$, where HR is heart rate and VTIlvot is the time integral of the velocity in the left ventricular outflow tract. ${ }^{17}$ Cardiac index was calculated as CO/BSA. Effective valve areas were calculated by means of both the standard continuity equation (VAstan = SV/VTIvalv, where SV is stroke volume and VTIvalv the time integral of the velocity through the valve) and the simplified equation (VAsimp $=\mathrm{A} \times$ Vlvot/Vvalv). ${ }^{18,19}$ The effective area index, a measure of how well the flow area of the valve matches body size, was calculated as VAstan/BSA.

Intralaboratory variability. To test intralaboratory variability in measurements of peak and mean gradients and effective valve areas, we repeated determinations of pulsed and continuous wave parameters and of left ventricular outflow tract diameter in 21 patients within 1 month of the postoperative echocardiographic examination. Variability was expressed as mean percent error, percent error being calculated as the absolute difference between the two observations divided by the mean of the two and expressed as a percentage (Table I).

Statistical analysis. Results are expressed as means \pm standard deviations. One-way analysis of variance was used to evaluate the significance of differences in measurements among valve sizes; if the $\mathrm{F}$ value was significant, the Tukey multiple comparison test was performed to assess differences between individual groups. Correlations between valve size and echocardiographic parameters were calculated by linear or second-degree polynomial regression analysis (or both) where appropriate. The significance of differences in the same group was estimated by means of Friedman's test. A probability $(p)$ value less than 0.05 was considered statistically significant.

\section{Results}

Tables II and III list preoperative characteristics of the four groups of patients defined by the size of the aortic prosthesis implanted. The patients in the larger valve size groups had significantly larger body surface areas than those in the smaller valve size groups, and they were approximately equally distributed between the sexes, whereas most patients receiving 19 or $21 \mathrm{~mm}$ prostheses were women. There were no statistically significant differences among the size groups as regards heart rate, blood pressure, degree of stenosis, or overall left ventricular systolic function. LVM and LVMI were significantly smaller 
Table III. Preoperative and postoperative echocardiographic data (preoperative values in parentheses)

\begin{tabular}{|c|c|c|c|c|}
\hline & \multicolumn{4}{|c|}{ Valve size (no. of patients) } \\
\hline & $19 \mathrm{~mm}(12)$ & $21 \mathrm{~mm}(15)$ & $23 \mathrm{~mm}(16)$ & $25 \mathrm{~mm}(9)$ \\
\hline \multirow[t]{2}{*}{ LVEDD $(\mathrm{mm})$} & $(40.2 \pm 5.8)$ & $(41.0+5.3)$ & $(43.2 \pm 6.1)$ & $(44.6 \pm 5.3)$ \\
\hline & $40.5 \pm 4.8$ & $40.8 \pm 5.1$ & $42.8 \pm 5.2$ & $43.9 \pm 4.9$ \\
\hline \multirow[t]{2}{*}{ IVST (mm) } & $(14.5 \pm 2.5)$ & $(15.3 \pm 2.8)$ & $(15.1 \pm 2.7)$ & $(14.8 \pm 2.4)$ \\
\hline & $13.5 \pm 2.6$ & $12.8 \pm 2.3 \dagger$ & $12.2 \pm 2.1 \dagger$ & $12.0 \pm 1.9 \dagger$ \\
\hline \multirow[t]{2}{*}{ PWT (mm) } & $(13.7 \pm 2.1)$ & $(14.2 \pm 2.5)$ & $(14.6 \pm 2.3)$ & $(14.1 \pm 2.1)$ \\
\hline & $12.7 \pm 1.8^{*}$ & $12.7 \pm 2.1^{*}$ & $11.8 \pm 2.0 \dagger$ & $11.7 \pm 2.0 \%$ \\
\hline \multirow[t]{2}{*}{ LVM (gm) } & $(240.5 \pm 49)$ & $(279.2 \pm 56)$ & $(303.1 \pm 61)$ & $(306.1 \pm 52)$ \\
\hline & $224.2 \pm 41$ & $217.5 \pm 43 \dagger$ & $214.2 \pm 45 \dagger$ & $218.7 \pm 42 \ddagger$ \\
\hline \multirow[t]{2}{*}{ LVMI $\left(\mathrm{r} / \mathrm{m}^{2}\right)$} & $(151.6 \pm 35)$ & $(170.2 \pm 49)$ & $(176.5 \pm 50)$ & $(171.8 \pm 41)$ \\
\hline & $137.8 \pm 30$ & $132.7 \pm 31 \dagger$ & $124.8 \pm 32 \ddagger$ & $124,6 \pm 30 \ddagger$ \\
\hline \multirow[t]{2}{*}{$\mathrm{FS}(\%)$} & $(33 \pm 5)$ & $(34 \pm 4)$ & $(30 \pm 6)$ & $(30 \pm 5)$ \\
\hline & $32 \pm 5$ & $34 \pm 5$ & $31 \pm 8$ & $30 \pm 7$ \\
\hline \multirow[t]{2}{*}{$\mathrm{EF}(\%)$} & $(64 \pm 7)$ & $(67 \pm 6)$ & $(61 \pm 9)$ & $(60 \pm 9)$ \\
\hline & $65 \pm 8$ & $67 \pm 9$ & $63 \pm 14$ & $61 \pm 11$ \\
\hline Time after operation (mo) & $18 \pm 11$ & $20 \pm 10$ & $16 \pm 12$ & $18 \pm 10$ \\
\hline
\end{tabular}

$L V E D D$, Left ventricular end-diastolic diameter; $I V S T$, interventricular septum thickness; $P W T$, left ventricular posterior wall thickness; FS, left ventricular fractional shortening; $E F$, left ventricular ejection fraction.

${ }^{*} p<0.05$ (postoperative versus preoperative values).

$\stackrel{t}{p}<0.01$ (postoperative verus preoperative values).

$\$ p<0.001$ (postoperative versus preoperative values).

Table IV. Ultrasonic hemodynamic data of different sizes of prosthetic heart valve in aortic position $($ mean $\pm S D)$

\begin{tabular}{|c|c|c|c|c|c|c|}
\hline & \multicolumn{4}{|c|}{ Valve size (mm) } & \multirow[b]{2}{*}{$F$} & \multirow[b]{2}{*}{$p$ Value } \\
\hline & $19(n=12)$ & $21(n=15)$ & $23(n=16)$ & $25(n=9)$ & & \\
\hline PSG (mm Hg) & $30.5 \pm 10$ & $21.4 \pm 11$ & $16.5 \pm 8$ & $16.4 \pm 7$ & 6.56 & 0.017 \\
\hline PSGc $(\mathrm{mm} \mathrm{Hg})$ & $25.8 \pm 9$ & $18.8 \pm 10$ & $15.1 \pm 6$ & $14.9 \pm 6$ & 6.11 & 0.021 \\
\hline MSG (mm Hg) & $18.3 \pm 7$ & $14.2 \pm 6$ & $9.1 \pm 5$ & $8.7 \pm 4$ & 4.98 & 0.039 \\
\hline Stroke volume (ml) & $58.7 \pm 13.1$ & $65.7 \pm 17.3$ & $68.2 \pm 11.9$ & $83.5 \pm 12.8$ & 3.1 & 0.05 \\
\hline $\begin{array}{l}\text { Cardiac index }(\mathrm{L} / \mathrm{min} / \mathrm{per} \\
\text { square meter) }\end{array}$ & $2.58 \pm 0.67$ & $2.60 \pm 0.56$ & $2.71 \pm 0.64$ & $2.59 \pm 0.59$ & 1.53 & 0.25 \\
\hline VAstan $\left(\mathrm{cm}^{2}\right)$ & $1.25 \pm 0.12$ & $1.48 \pm 0.13$ & $1.80 \pm 0.24$ & $2.09 \pm 0.28$ & 18.7 & $<0.001$ \\
\hline VAsimp $\left(\mathrm{cm}^{2}\right)$ & $1.18 \pm 0.14$ & $1.43 \pm 0.14$ & $1.78 \pm 0.22$ & $1.86 \pm 0.20$ & 19.6 & $<0.001$ \\
\hline Effective area index & $0.79 \pm 0.11$ & $0.89 \pm 0.09$ & $1.04 \pm 0.23$ & $1.17 \pm 0.16$ & 10.5 & $<0.001$ \\
\hline
\end{tabular}

$P S G$, Peak transvalvular pressure drop; $P S G c$, peak transvalvular pressure drop corrected for prevalvular velocity; $M S G$, mean transvalvular pressure drop; VAsimp, VAstan, valve areas calculated by means of the simplified and standard continuity equations.

in the $19 \mathrm{~mm}$ group than in any of the others, but the latter did not differ significantly one from another.

Table III compares preoperative and postoperative echocardiographic parameters for each valve size group. There were no significant changes in diameters or in left ventricular systolic function parameters, but LVM and LVMI decreased in all four groups (albeit nonsignificantly in the $19 \mathrm{~mm}$ group and with less statistical significance in the 21 mm group than in the 23 and $25 \mathrm{~mm}$ groups). In no prosthesis size group was there a significant difference between patients with mechanical prostheses and patients with bioprostheses as regards either preoperative or postoperative LVM.
In 45 of the 52 prostheses $(86.5 \%)$, the greatest velocities were recorded from apical views. The greatest subvalvular velocity measured after the operation was $1.65 \mathrm{~m} / \mathrm{sec}$. There was a significant negative correlation between subvalvular diameter and outflow tract velocity $(r=-0.65, p<0.001 ; n=$ 52). Postoperative peak and mean transvalvular pressure drops were significantly greater in the 19 mm group than in the other groups. The 21 and 23 $\mathrm{mm}$ groups did not differ significantly in this respect, and neither did the 23 and $25 \mathrm{~mm}$ groups, but transvalvular pressure drops in the $21 \mathrm{~mm}$ group were significantly greater than those in the $25 \mathrm{~mm}$ group (Table IV and Fig. 1). There were significant 


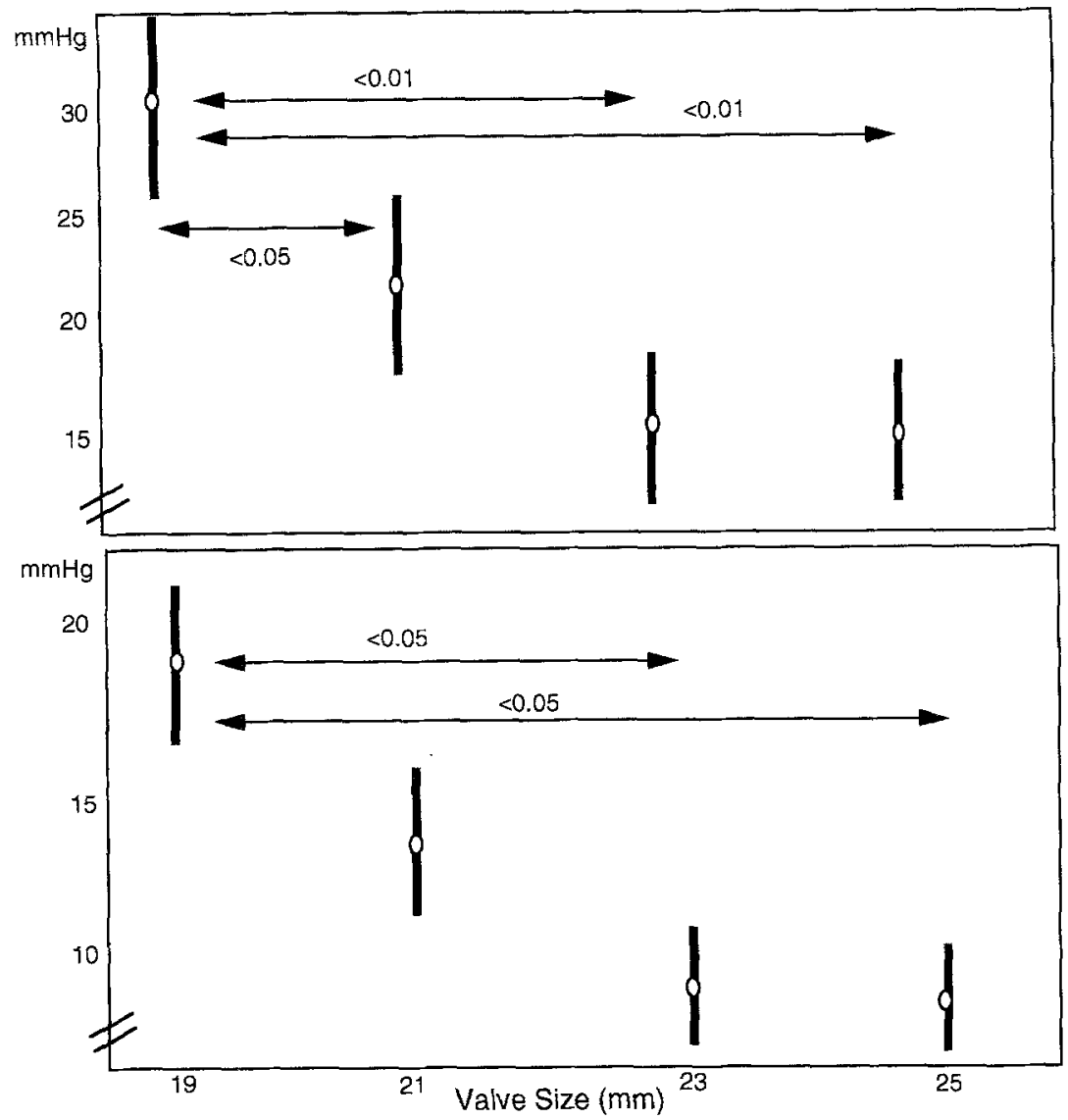

Fig. 1. Plots of mean \pm standard deviation peak (upper panel) and mean (lower panel) transvalvular pressure drops against aortic valve prosthesis size. Only statistically significant comparisons are indicated.

negative correlations between valve size and peak and mean transvalvular pressure drops $(r=-0.64$ and $r=-0.72$, respectively; $p<0.001$ in both cases).

The prosthetic valve areas calculated from the simplified continuity equation correlated well with those given by the standard equation (VAsimp = $0.92 \times$ VAstan $+0.12 ; r=0.91$, standard error of the estimate $=0.07$ ). Postoperative effective valve area was significantly smaller in the $19 \mathrm{~mm}$ group than in the $21 \mathrm{~mm}$ group and significantly smaller in the $21 \mathrm{~mm}$ group than in the 23 and $25 \mathrm{~mm}$ groups, but there was no statistically significant difference between the latter two groups (Table IV and Fig. 2). There was good linear correlation between effective valve area and nominal valve size $(r=0.90, p<$ 0.001 ), and analysis of variance showed the four size groups to be better differentiated by effective valve area $(F=18.7$ for VAstan, $F=19.6$ for VAsimp; $p<0.001$ in both cases) than by PSG ( $F=6.56$, $p=0.017)$ or MSG $(F=4.98, p=0.039)$; but the effective area index also increased with valve size $(r=0.85, p<0.001)$, showing valve prosthesispatient mismatch. In no prosthesis size group was there a significant difference between patients with mechanical prostheses and patients with bioprostheses as regards valve hemodynamics (PSG, MSG, or effective valve area).

Pandiastolic regurgitation was observed in apical continuous Doppler records in all 32 patients with mechanical prostheses and in $16(53 \%)$ of those with bioprostheses (14 with Labcor-Santiago valves and 2 with MitroFlow valves). Peak regurgitation velocity was in all cases less than $1.7 \mathrm{~m} / \mathrm{sec}$, and it was significantly less for the bioprostheses than for the mechanical prostheses, $0.6 \pm 0.3 \mathrm{~m} / \mathrm{sec}$ as against $1.3 \pm 0.3 \mathrm{~m} / \mathrm{sec}(p<0.01)$. Leakage penetrated 1 to $3 \mathrm{~cm}$ into the ventricle and was deemed slight or negligible. Color flow echocardiograms from apical (two- or four-chamber views) or long-axis parasternal views showed regurgitation jets in all 38 of these patients. The mechanical valves exhibited two lat- 


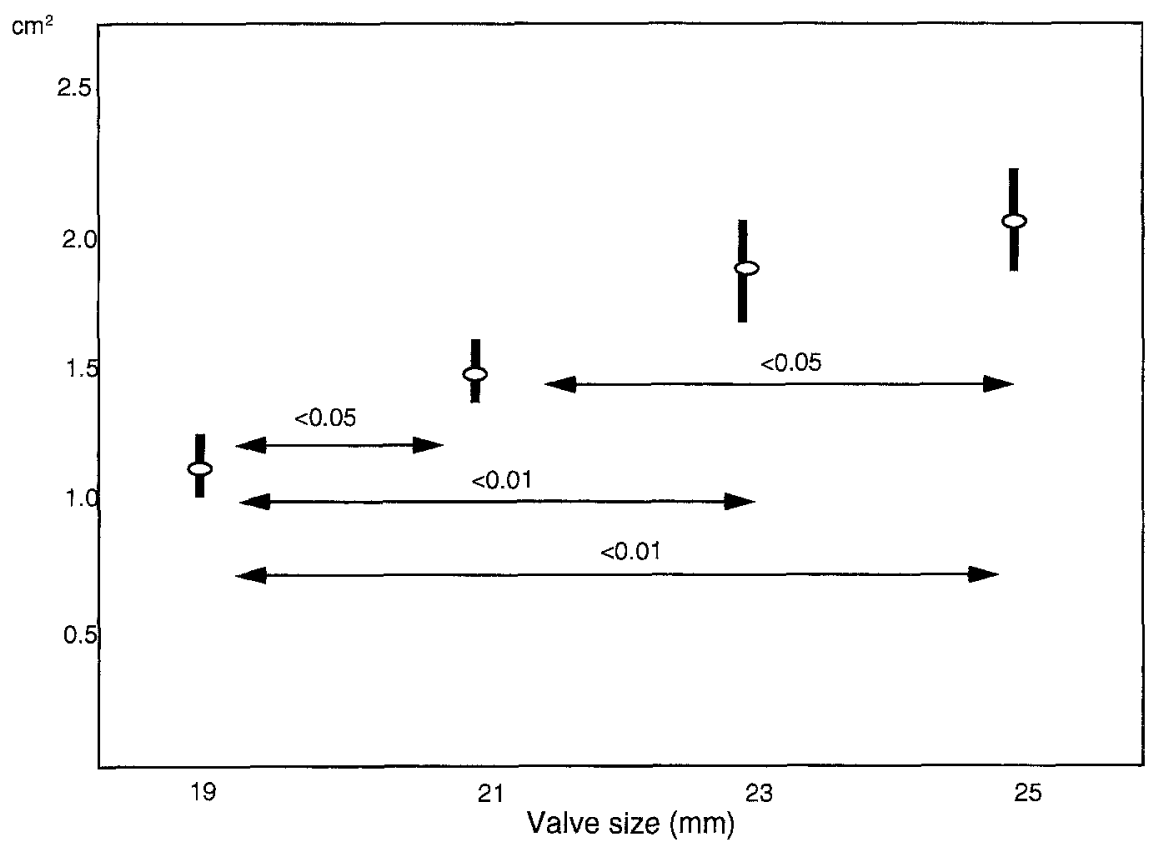

Fig. 2. Plot of mean \pm standard deviation effective valve area against aortic valve prosthesis size. Only statistically significant comparisons are indicated.

eral jets and a minor central jet, except one which, like 8 of the 16 regurgitating bioprostheses, had a larger central jet and no lateral jets. Aortic regurgitation was uniformly distributed among the various valve sizes.

\section{Discussion}

Doppler echocardiography is currently the most widely used technique for clinical evaluation of artificial heart valves; estimates of functional parameters obtained through Doppler echocardiographic measurements correlate well with those obtained by invasive methods, ${ }^{8,12,13}$ which can no longer be justified for the evaluation of normally functioning valves. Measurements obtained by the two kinds of technique are nevertheless not directly comparable; transvalvular pressure drop values determined by Doppler echocardiography are greater than those determined by invasive procedures. ${ }^{1,20}$ For example, Ihlen and coworkers ${ }^{20}$ reported that echocardiographically measured mean pressure drops across CarboMedics prostheses in the aortic position exceeded those measured with catheters by $4.4 \pm 4.8 \mathrm{~mm} \mathrm{Hg}$. The reason for this difference appears to be that in clinical studies catheter tips are usually located more than $2 \mathrm{~cm}$ from the plane where pressure recovery occurs: in an in vitro study of the St Jude Medical valve ${ }^{21}$ (St. Jude Medical,
Inc., St. Paul, Minn.), echocardiographically measured pressure drops agreed fully with catheter measurements taken at valve level but were $10.3 \pm$ $2.5 \mathrm{~mm} \mathrm{Hg}$ greater than catheter measurements taken $3 \mathrm{~cm}$ from the valve.

Although aortic transvalvular pressure drops are influenced by transvalvular flow rate, which should be taken into account in evaluating their clinical significance, they probably depend most on the diameter of the valve ring, increasing with decreasing ring size. In this study there was a significant negative correlation between valve size and peak and mean transvalvular pressure drops.

In a recent study, we ${ }^{14}$ found no significant difference between the hemodynamic performance of $19 \mathrm{~mm}$ pericardial bioprostheses and that of $19 \mathrm{~mm}$ bileaflet mechanical prostheses in the aortic position; as in other studies of the hemodynamics of small prostheses, $1,22,22-24$ in which effective valve areas of 0.9 to $1.2 \mathrm{~cm}^{2}$ and mean PSGs as high as 40 $\mathrm{mm} \mathrm{Hg}$ have been observed, transvalvular pressure drops and effective valve areas were far from satisfactory. These findings, together with recent reports that patients with small (19 or $21 \mathrm{~mm}$ ) prostheses have a poorer prognosis than those with larger prostheses, ${ }^{25}$ must be taken into account when planning operations for patients for whom aortic valve replacement is indicated. 
In patients with aortic stenosis, left ventricular pressure is chronically elevated. LVH occurs as an adaptive response and, initially, keeps left ventricular stress (the force generated by each unit of myocardium) within the normal range. Hypertrophy can be quantitated by echocardiography. In relatively symmetric ventricles, without left ventricular aneurysm or diastolic shape abnormality caused by marked dilation of the right side of the heart (conditions shared by all the patients in this study), this can be done by means of measurements obtained in the $M$ mode $^{15}$ : echocardiographic estimates of LVM calculated from Devereux and Reichek's formula correlate well with angiographic estimates of LVM, with postmortem left ventricular weight, and with estimates obtained by applying Simpson's rule or an area-length formula to twodimensional echocardiographic measurements. New imaging techniques, such as nuclear magnetic resonance imaging and ultrafast computed tomography, provide images of the beating heart with high temporal and spatial resolution allowing more precise calculation of volumes and LVM, but echocardiography is still the most cost-efficient method.

The treatment of aortic stenosis by valve replacement is usually followed by the reduction of LVH by an amount variously reported as being between $16 \%$ and 44\% ${ }^{26-29}$ Most regression occurs during the first 6 months after the operation. However, most studies of this phenomenon have involved patients with valves of size $21 \mathrm{~mm}$ or more; the available information on patients with $19 \mathrm{~mm}$ valves is scant. Sim and associates, ${ }^{30}$ in a retrospective study of 39 of 714 patients in whom aortic valve prostheses of size 19 , 21 , or $23 \mathrm{~mm}$ had been implanted (accompanied by aortic ring enlargement in 168 cases), found that patients with a $19 \mathrm{~mm}$ aortic prosthesis and no other prostheses exhibited no significant reduction in LVM a mean of 26 months after the operation, whereas those with 21 or $23 \mathrm{~mm}$ prostheses did exhibit regression, and to similar extents. However, inasmuch as the 10 patients with $19 \mathrm{~mm}$ prostheses had preoperative LVMIs of $129 \pm 47 \mathrm{gm} / \mathrm{m}^{2}$ (i.e., only slightly above normal, despite their having mean aortic pressure drops and valve areas suggestive of severe aortic stenosis), whereas the 21 and 23 $\mathrm{mm}$ groups had preoperative LVMIs of $150 \mathrm{gm} / \mathrm{m}^{2}$ or more, Sirn and coworkers ${ }^{30}$ suggested that the surgeons in their institution might have chosen to implant 19 mm valves only in patients with no more than slight LVH. Certainly, the scant ventricular hypertrophy of Sim's $19 \mathrm{~mm}$ group, and the small size of the study (39 patients) in relation to the 714 patients in whom aortic valves had been implanted, oblige one to treat their findings with some reserve. Nevertheless, in our study we also found significant postoperative reduction in LVM in patients with 21 to $25 \mathrm{~mm}$ aortic prostheses but not in patients with $19 \mathrm{~mm}$ prostheses (despite the postoperative effective valve areas of the latter group having been, as in the study by Sim and associates, almost double their preoperative areas); although the $19 \mathrm{~mm}$ group had less severe LVH than the other groups, their preoperative LVMIs were far above the upper limit of the normal range (possibly because almost all the patients in this group were women).

The lack of a significant reduction in LVM in our 19 mm group may have been due to a number of factors: (1) regression of LVH being slower in these patients than in the recipients of larger valves (although all the patients with $19 \mathrm{~mm}$ prostheses had their follow-up examination more than 10 months after their operations); (2) this group being older than the others (age is an independent determinant of $\mathrm{LVM}^{31}$ ); and (3) the suboptimal hemodynamics of $19 \mathrm{~mm}$ prostheses at rest and during exercise. We are currently evaluating hemodynamics during exercise as part of a longer-term (3- to 5-year) study of patients with aortic valve prostheses implanted to replace stenotic native valves. The failure of small aortic prostheses to reduce LVM may be related to the results of several studies showing their recipients to have a poorer prognosis than recipients of larger valves.

We conclude that despite undeniable recent improvements in the design of artificial heart valves, 19 $\mathrm{mm}$ aortic prostheses continue to create a significant obstruction of the left ventricular outflow tract and, possibly as a consequence of this, fail to bring about significant reduction in LVH. Aortic prostheses of this size should probably not be implanted in young or physically active patients or in patients with body surface areas greater than $1.7 \mathrm{~m}^{2}$. Instead, aortic valve replacement in these groups of patients should probably be effected by means of a homograft or by implantation of a $21 \mathrm{~mm}$ or larger valve after aortic root enlargement.

REFERENCES

1. Bojar RM, Diehl JT, Motten M, et al. Clinical and hemodynamic performance of the Ionescu-Shiley valve in the small aortic root: results in 117 patients with 17 and $19 \mathrm{~mm}$ valves. J Thorac Cardiovasc Surg 1989;98:1087-95.

2. Wiseth R, Levang OW, Sande E, Tanger G, Skjaerpe T, Hatle L. Hemodynamic evaluation by Doppler echocardiog- 
raphy of small $(<21 \mathrm{~mm})$ prostheses and bioprostheses in the aortic valve position. Am J Cardiol 1992;70:240-6.

3. Bove EL, Marvasti MA, Potts JL. Rest and exercise hemodynamics following aortic valve replacement: a comparison between 19 and $21 \mathrm{~mm}$ Ionescu-Shiley pericardial and Carpentier-Edwards porcine valves. J Thorac Cardiovasc Surg 1985;90:750-5.

4. Abdelnoor M, Hall KV, Nitter-Hauge S, Lindberg H, Ovrum E. Prognostic factors in aortic valve replacement associated with narrow aortic roots. Scand J Thorac Cardiovasc Surg 1986;20:227-32.

5. González-Juanatey JR, Garcia-Bengoechea JB, Vega M, Rubio J, Sierra J, Duran D, et al. Echocardiographic features of the normofunctional Labcor-Santiago pericardial bioprosthesis. J Heart Valv Dis 1994;3:548-55.

6. Konno S, Imai Y, Nakajima M, Tatsuno K. A new method for prosthetic valve replacement in congenital aortic stenosis associated with hypoplasia of the aortic valve ring. $\mathbf{J}$ Thorac Cardiovasc Surg 1975;70:909-17.

7. Manouguian S, Seybold-Epting W. Patch enlargement of the aortic valve ring by extending the aortic incision into the anterior mitral leaflet: new operative technique. J Thorac Cardiovasc Surg 1979;78:402-12.

8. Chambers J, Fraser A, Lawford P, Nihoyannopoulos P, Simpson I. Echocardiographic assessment of artificial heart valves: British Society of Echocardiography position paper. Br Heart J (Suppl) 1994;71:6-14.

9. Sullivan JM, Vander Swagg R, El-Zeky F, Ramanathan KB, Mirvis DM. Left ventricular hypertrophy: effect on survival. J Am Coll Cardiol 1993;22:508-13.

10. Levy D, Salomon M, D'Agostino RB, Belanger AJ, Kannel WB. Prognostic implications of baseline electrocardiographic features and their serial changes in subjects with left ventricular hypertrophy. Circulation 1994;90:1786-93.

11. Orsinelli DA, Aurigemma GP, Battista S, Krendel S, Gaasch WH. Left ventricular hypertrophy and mortality after aortic valve replacement for aortic stenosis: a high risk subgroup identified by preoperative relative wall thickness. J Am Coll Cardiol 1993;22:1679-83.

12. Chambers JB, Deverall PB. Limitations and pitfalls in the assessment of prosthetic valves with Doppler ultrasonography. J Thorac Cardiovasc Surg 1992;104:495-501.

13. Alam M, Rosman HS, Lakier JB, Kemp S, Shaja F, Hautamaki K, et al. Doppler and echocardiographic features of normal and dysfunctioning bioprosthetic valves. J Am Coll Cardiol 1987;10:851-8.

14. González-Juanatey JR, García-Acuña JM, Amaro A, Castelo V, Pedreira M, García-Bengochea JB, et al. Doppler echocardiographic comparison of small $(19 \mathrm{~mm})$ bileaflet and pericardial heart valve prostheses in aortic position. Scand $\mathbf{J}$ Thorac Cardiovasc Surg 1995;29:29-35.

15. Devereux RB, Reichek N. Echocardiographic determination of left ventricular mass in men: anatomic validation of the method. Circulation 1977;55:613-8.

16. Hatle L, Angelsen B. Pressure velocity relationships. In: Doppler ultrasound in cardiology: physical principles and clinical applications. 2nd ed. Philadelphia: Lea \& Febiger, 1985:22-6.
17. Ihlen H, Molstad P. Cardiac output measured by Doppler echocardiography in patients with aortic prosthetic valves. Eur Heart J 1990;11:399-402.

18. Skjaerpe T, Hegrenaes L, Hatle L. Noninvasive estimation of valve area in patients with aortic stenosis by Doppler ultrasound and two-dimensional echocardiography. Circulation 1985;72:810-8.

19. Zoghbi WA, Farmer KL, Soto JG, Nelson JG, Quinones MA. Accurate noninvasive quantification of the stenotic aortic valve area by Doppler echocardiography. Circulation 1986; 73:452-9.

20. Ihlen H, Molstad P, Siminsen S, et al. Hemodynamic evaluation of the CarboMedics prosthetic heart valve in the aortic position: comparison of noninvasive and invasive techniques. Am Heart J 1992;123:151-9.

21. Baumgartner H, Khan S, DeRobertis M, Czer L, Maurer C. Discrepancies between Doppler and catheter gradients in aortic prosthetic valves in vitro: a manifestation of localized gradients and pressure recovery. Circulation 1990;82:1467-75.

22. Chambers J, Cross J, Deverall P, Sowton E. Echocardiographic description of the CarboMedics bileaflet prosthetic valve. J Am Coll Cardiol 1993;21:398-405.

23. Aupart M, Neville P, Dreyfus X, Meurisse Y, Sirinelli A, Marchand $M$. The Carpentier-Edwards pericardial aortic valve: intermediate results in 420 patients. Eur J Cardiothorac Surg 1994;8:277-80.

24. Badano L, Bertoli D, Astengo D, et al, on behalf of the Valve Prostheses Ligurian Cooperative Doppler Study. Doppler haemodynamic assessment of clinically and echocardiographically normal mitral and aortic Allcarbon valve prostheses. Eur Heart J 1993;14:1602-9.

25. Kratz JM, Sade RM, Crawford FA Jr, Crumbley AJ III, Stroud MR. The risk of small St Jude aortic valve prostheses. Ann Thorac Surg 1994;57:1114-9.

26. Pantley G, Morton M, Rahimtoola SH. Effects of successful uncomplicated valve replacement on ventricular hypertrophy, volume and performance in aortic stenosis and aortic incompetence. J Thorac Cardiovasc Surg 1978;75: 383-91.

27. Koudelkova E. Regression of left ventricular hypertrophy after aortic valve replacement. Acta Univ Carol 1984;30:495520 .

28. Hess OM, Ritter M, Schneider J, Grimm J, Turina M, Krayenbuehl HP. Diastolic stiffness and myocardial structure in aortic valve disease before and after aortic valve replacement. Circulation 1984;69:855-65.

29. Kennedy JW, Doces J, Stewart DK. Left ventricular function following aortic valve replacement. Circulation 1977;56:94450.

30. Sim EKW, Orszulak TA, Schaff HV, Shub C. Influence of prosthesis size on change in left ventricular mass following aortic valve replacement. Eur J Cardiothorac Surg 1994;8: 293-7.

31. Messerli FH. Clinical determinants and manifestations of left ventricular hypertrophy. In: Messerli FH, editor. The heart and hypertension. New York: Yorke Medical Books, 1987: 219-30. 